Fourth International Conference on Sustainable Construction Materials and Technologies http://www.claisse.info/Proceedings.htm

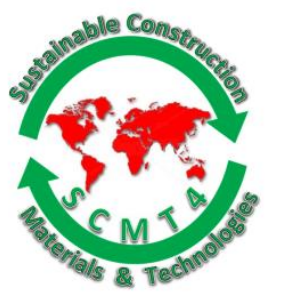

SCMT4

Las Vegas, USA, August 7-11, 2016

\title{
Comparison between Ultra-High-Performance Concretes with Recycled Steel Fiber and Normal Industrial Steel Fiber
}

\author{
G.F. Peng ${ }^{1 \mathrm{a}}$, J. Yang ${ }^{1 \mathrm{~b}}$, Q.Q. Long $^{1 \mathrm{c}}$, X.J. Niu ${ }^{1 \mathrm{~d}}$, and Q.P. Zeng ${ }^{1 \mathrm{e}}$ \\ ${ }^{1}$ Faculty of Civil Engineering and Architecture; Beijing Jiaotong University, No.3 Shangyuancun, Haidian \\ District, Beijing, P. R. China. \\ ${ }^{1 a}$ Email: <gfpeng@bjtu.edu.cn>, ${ }^{1 b}$ Email: <wechico@163.com>, ${ }^{1 c}$ Email:<349591663@qq.com>, \\ ${ }^{1 d}$ Email: $<14115296 @ b j t u . e d u . c n>,{ }^{1 e}$ Email:<14121138@bjtu.edu.cn>.
}

\begin{abstract}
Recycled steel fiber processed from waste tires were used to prepare ultra-high- performance concrete. Ultra-high-performance concrete with normal industrial steel fiber and plain concrete without any steel fiber were also prepared for comparison. Experimental investigations were conducted to determine the mechanical properties of ultra-high-performance concretes, including compressive strength, splitting tensile strength, fracture energy and elastic modulus. Additionally, explosive spalling of concretes exposed to high temperature up to $800{ }^{\circ} \mathrm{C}$ was also tested. The recycled tire steel fiber could improve the fracture energy of concrete more significantly than normal industrial steel fiber. The splitting tensile strength of the recycled tire steel fiber reinforced concrete was also the highest among these concretes with various steel fibers. Moreover, the recycled steel fiber presented better behavior to resist the explosive spalling of the ultra-high-performance concrete. It is concluded that the recycled tire steel fiber help ultra-highperformance concrete possess higher toughness in terms of fracture energy and higher cracking resistance, so as to have higher resistance to thermally explosive cracking.
\end{abstract}

\section{INTRODUCTION}

Environmental concerns associated with waste rubber tires have attracted research attention in recent years. Recycling of waste rubber tires was focused on the extracted rubbers and steel fiber. A large amount of researches on the application of tire rubbers in many types of concretes have been reported, such as the roller compacted concrete, engineered cementitious composites, high performance concrete, asphalt concrete and pervious concrete (Meddah \& Gesog lu 2014, Huang \& Yung 2013, Azevedo 2012, Long 2011, Tortum 2005).

It was found that mechanical properties of concretes reinforced by the recycled steel fiber from tires were comparable to that with industrial steel fiber (Centonze 2012, Aiello 2009). M.A. Aiello reported bond characteristic between recycled steel fiber and concrete matrix by pull-out test of the concrete specimens with a single recycled steel fiber embedded centrally (Aiello 2009). It was also found that the concrete pavement thickness could be reduced up to $26 \%$ because of the addition of recycled steel fiber, when only 
taking into account of their effect on fatigue property (Graeffang 2012). A research was carried out to evaluate the suitability of existing RILEM design framework (Neocleous \& Tlemat 2006). An economic analysis was performed on recycled steel fiber reinforced concretes and it can be found that, if the recycled steel fiber was used alone, savings of up to 33\% can be realized (Bjegovic 2012). Moreover, a research on the fracture properties of recycled steel fiber reinforced concrete with crumb rubber when subjected to high temperature indicated that, the fracture energy of concrete was increased with increasing temperature because of the thermal effect on the crack growth (Guo 2014).

Ultra-high-performance concrete (UHPC) has been widely used in practical structures. However, since the brittleness of UHPC is rather high, adding fiber is a usual approach to improve the toughness of UHPC. When UHPC was exposed to high temperature, explosive spalling would occur (Hosser 2012). It was confirmed that steel fiber can present a beneficial effect on inhibiting the explosive spalling of concrete subjected to high temperature (Peng 2008).

In this investigation, mechanical properties of UHPC reinforced by recycled steel fiber and the plain concrete, including compressive strength, splitting tensile strength and fracture energy, were determined. Explosive spalling of UHPC was tested. For comparison purpose, normal industrial steel fiber was also used.

\section{EXPERIMENTAL DETAILS}

\section{General}

Concretes were prepared using basalt with two particle sizes in the ranges of $5 \sim 10 \mathrm{~mm}$ and $10 \sim 16 \mathrm{~mm}$ as coarse aggregate, the mass proportion of which was 3:7. Its physical properties are listed in Table 1. Artificial sand was used as fine aggregate, obtained by crushing limestone. Its physical properties are given in Table 2. Portland cement of 52.5R grade and silica fume (SF) were used, and their properties are listed in Table 3 and Table 4. Five types of steel fiber used are shown in figure 1 and Table 5. Superplasticizer of polycarboxylate type with a solid content of $50 \%$ was used to control the slump of fresh concrete at approximately $250 \mathrm{~mm}$, and the slump spread between $560 \mathrm{~mm} \sim 585 \mathrm{~mm}$.

Table 1. Physical properties of coarse aggregate

\begin{tabular}{|c|c|c|c|}
\hline Type & Apparent density $\left(\mathrm{kg} / \mathrm{m}^{3}\right)$ & Packing density $\left(\mathrm{kg} / \mathrm{m}^{3}\right)$ & Crushing index \\
\hline Basalt & 3030 & 1790 & $3.1 \%$ \\
\hline
\end{tabular}

Table 2. Physical properties of artificial sand

\begin{tabular}{|c|c|c|c|c|c|}
\hline $\begin{array}{c}\text { Fineness } \\
\text { modulus }\end{array}$ & $\begin{array}{c}\text { Apparent density } \\
\left(\mathrm{kg} / \mathrm{m}^{3}\right)\end{array}$ & $\begin{array}{c}\text { Packing density } \\
\left(\mathrm{kg} / \mathrm{m}^{3}\right)\end{array}$ & $\begin{array}{c}\text { Mud } \\
\text { content }(\%)\end{array}$ & $\begin{array}{c}\text { Clay pieces } \\
\text { content }(\%)\end{array}$ & $\begin{array}{c}\text { Stone power } \\
\text { content }(\%)\end{array}$ \\
\hline 2.94 & 2600 & 1650 & 5.5 & 0.5 & 5.5 \\
\hline
\end{tabular}

Table 3. Properties of cement

\begin{tabular}{|c|c|c|c|c|c|c|}
\hline Cement & $\begin{array}{c}\text { Initial setting } \\
\text { time (min) }\end{array}$ & \multirow{2}{*}{$\begin{array}{c}\text { Finial setting } \\
\text { time (min) }\end{array}$} & \multicolumn{2}{|c|}{ Flexural strength (MPa) } & \multicolumn{2}{|c|}{ Compressive strength (MPa) } \\
\cline { 4 - 7 } & & 3 days & 28 days & 3 days & 28 days \\
\hline $52.5 \mathrm{R}$ & 137 & 194 & 7.4 & 9.0 & 37.4 & 62.0 \\
\hline
\end{tabular}


Table 4. Physical properties of silica fume

\begin{tabular}{|c|c|c|c|}
\hline Mineral material & Density $\left(\mathrm{kg} / \mathrm{m}^{3}\right)$ & Blaine specific surface $\left(\mathrm{m}^{2} / \mathrm{kg}\right)$ & Loss on ignition (\%) \\
\hline $\mathrm{SF}$ & 2200 & 22205 & 1.73 \\
\hline
\end{tabular}

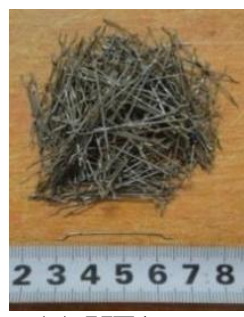

(a) HF1

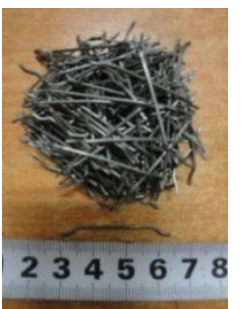

(b) HF2

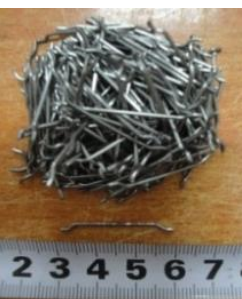

(c) HF3

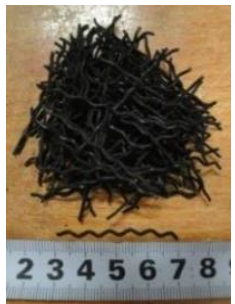

(d) RSF

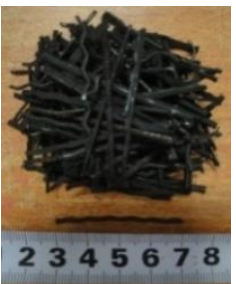

(e) RSFR

Figure 1. Outlook of steel fiber in this investigation

Table 5. Characterization of steel fiber

\begin{tabular}{|c|c|c|c|c|c|}
\hline \multirow{2}{*}{ Types } & \multicolumn{3}{|c|}{ Industrial steel fiber } & \multicolumn{2}{c|}{ Recycled Steel fiber* } \\
\cline { 2 - 6 } & HF1 & HF2 & HF3 & RSF & RSFR \\
\hline Shape & Hooked & Hooked & Hooked & Crimped & Crimped \\
\hline Nominal length (mm) & 35 & 35 & 30 & 40 & 40 \\
\hline Nominal diameter (mm) & 0.55 & 1 & 1 & 1 & 1.1 \\
\hline Aspect ratio & 64 & 35 & 30 & 40 & 40 \\
\hline Tensile strength (MPa) & 1100 & 900 & $1800-2000$ & $>1250$ & $1800-2000$ \\
\hline
\end{tabular}

*Recycled steel fiber attached rubber (RSFR) was treated by approximately $450^{\circ} \mathrm{C}$ high temperature processing techniques to dispose of the rubber, and then recycled steel fiber unattached rubber (RSF) was obtained, presenting lower tensile strength than RSFR.

Six types of UHPC were prepared as $100 \times 100 \times 100 \mathrm{~mm}$ cubes and $100 \times 100 \times 300 \mathrm{~mm}$ beams, with various types of steel fiber, which were designated as 0.18UHPC-Plain, 0.18UHPC-HF1, 0.18UHPC-HF2, $0.18 \mathrm{UHPC}-\mathrm{HF} 3,0.18 \mathrm{UHPC}-\mathrm{RSF}$ and $0.18 \mathrm{UHPC}-\mathrm{RSFR}$. The mix proportions are given in Table 6 . After casting, each specimen was covered with plastic film immediately to minimize moisture loss, followed by the storage under room temperature for 24 hours. These specimens were then demolded and cured in water under temperature of $20^{\circ} \mathrm{C}$ for 56 days. Thereafter, the tests were performed.

Table 6. Mix proportions of UHPC $\left(\mathrm{kg} / \mathrm{m}^{3}\right)$

\begin{tabular}{|c|c|c|c|c|c|c|c|c|}
\hline \multirow[t]{2}{*}{ Types } & \multirow[t]{2}{*}{$\mathrm{W} / \mathrm{B}$} & \multicolumn{2}{|c|}{ Binders } & \multirow{2}{*}{$\begin{array}{l}\text { Artificial } \\
\text { Sand }\end{array}$} & \multirow{2}{*}{$\begin{array}{c}\text { Coarse } \\
\text { aggregate }\end{array}$} & \multicolumn{3}{|c|}{ Steel fiber } \\
\hline & & $\mathrm{C}$ & SF & & & Shape & Type & content \\
\hline 0.18UHPC-Plain & 0.18 & 810 & 810 & 620 & 930 & - & - & 0 \\
\hline 0.18UHPC-HF1 & 0.18 & 810 & 810 & 620 & 930 & Hooked & HF1 & 30 \\
\hline 0.18 UHPC-HF2 & 0.18 & 810 & 810 & 620 & 930 & Hooked & HF2 & 30 \\
\hline 0.18 UHPC-HF3 & 0.18 & 810 & 810 & 620 & 930 & Hooked & HF3 & 30 \\
\hline 0.18 UHPC-RSF & 0.18 & 810 & 810 & 620 & 930 & Crimped & $\mathrm{RSF}$ & 30 \\
\hline 0.18UHPC-RSFR & 0.18 & 810 & 810 & 620 & 930 & Crimped & RSFR & 30 \\
\hline
\end{tabular}




\section{Determination of mechanical properties of concrete}

Specimens of $100 \mathrm{~mm}$ cube were used for determining compressive strength and splitting tensile strength. Notched beam specimens of $100 \times 100 \times 300 \mathrm{~mm}$ were used to determine fracture energy of UHPC. Determination of fracture energy followed the procedure described by Peng (2006). Each value presented in the study was an average of the results of three specimens a group at 56 days. The broken surfaces of specimens after fracture energy test were used for observation by an optical microscope.

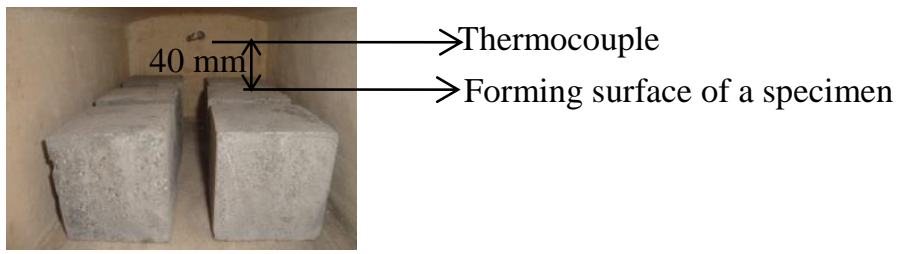

Figure 2. Location of the thermocouple in the electric furnace

\section{Explosive spalling test}

Explosive spalling test was conducted on six $100 \mathrm{~mm}$ cube specimens a group for a given type of concrete at 365 days age. The specimens were heated in an electric furnace at a rate of approximately $10{ }^{\circ} \mathrm{C} / \mathrm{min}$, and the inside temperature of furnace was measured with a thermocouple at a position approximately 40 $\mathrm{mm}$ above the specimens, as shown in figure 2 .

\section{RESULTS AND DISCUSSIONS}

\section{Compressive strength}

Compressive strength of concretes is presented in figure 3. It can be seen that, compressive strength of UHPC with HF3, HF1, RSF and HF2 was higher than that of plain concrete without steel fiber and the increment was different for the various types of steel fiber, which was $13.9 \%, 7.1 \%, 4.3 \%$ and $3.2 \%$, respectively. The compressive strength of $0.18 \mathrm{UHPC}-\mathrm{HF} 3$ was the highest. The increment was only 5.8 $\mathrm{MPa}$ and 4.3 MPa for 0.18UHPC-RSF and 0.18UHPC-HF2, respectively. Moreover, RSFR had a slightly adverse effect on the compressive strength. Compared with 0.18UHPC-Plain, the compressive strength of 0.18UHPC-RSFR decreased 5.3 MPa approximately.

During loading, plain concrete specimens encountered typical brittle explosive failure, accompanied by a loud noise.

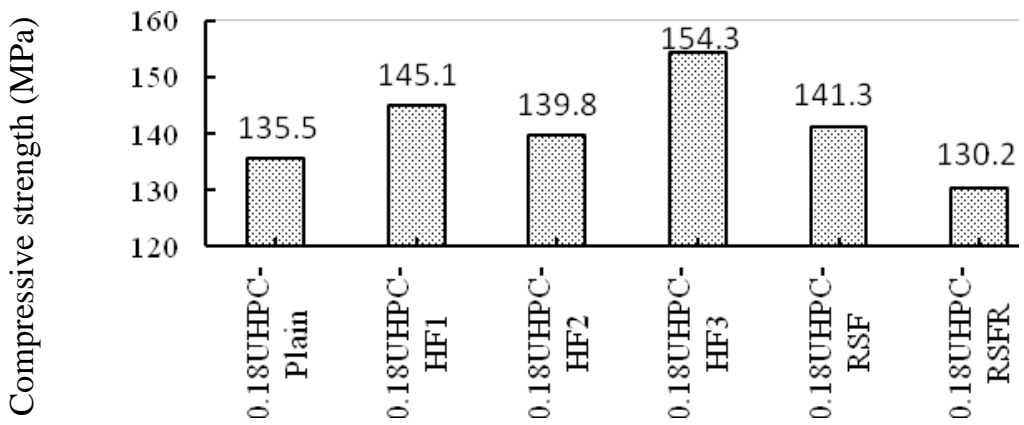

Figure 3. Compressive strength of UHPC with various steel fibers and the plain concrete 


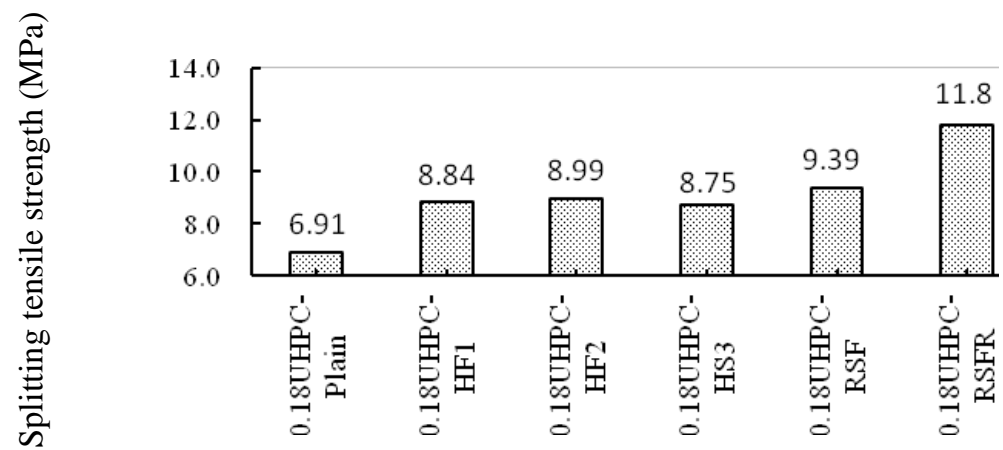

Figure 4. Splitting tensile strength of UHPC with various steel fibers and the plain concrete

\section{Splitting tensile strength}

The results of splitting tensile strength are given in figure 4. It can be found that, the splitting tensile strength of all steel fiber reinforced concretes was higher than that of plain concrete, and the increment of splitting tensile strength of UHPC reinforced by industrial steel fiber of HF1, HF2 and HF3 was 27.9\%, $30.1 \%, 26.6 \%$, respectively. The effect of RSF or RSFR on improving splitting tensile strength of UHPC was better than that of the industrial steel fiber, and the increment was $7.3 \%$ and $34.9 \%$, respectively.

The steel fiber of RSFR improved splitting tensile strength of UHPC significantly. It may be due to the cracking-resistance of this type of steel fiber and a higher tensile strength of RSFR itself.

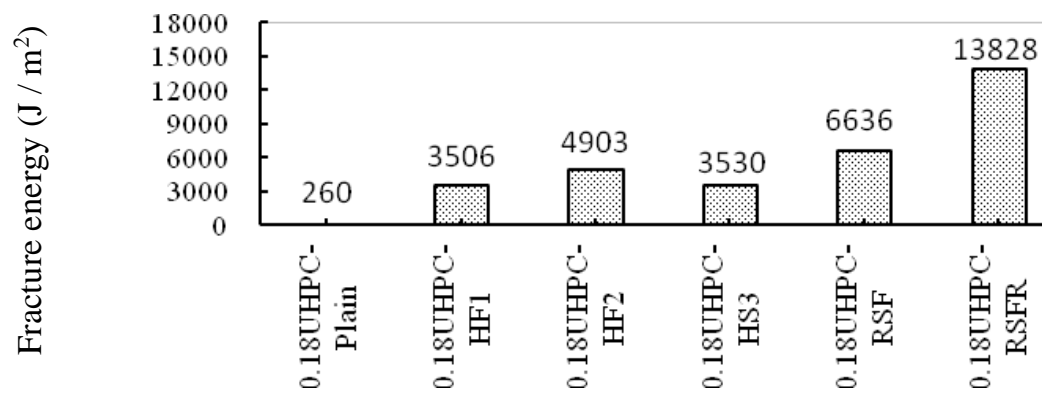

Figure 5. Fracture energy of UHPC with various steel fibers and the plain concrete

\section{Fracture energy}

As shown in figure 5, fracture energy of all steel fiber reinforced concretes was obviously higher than that of plain concrete. In particular, the recycled steel fiber significantly improved the fracture energy of UHPC. It means that the capacity of UHPC to absorb energy can be greatly improved by recycled steel fiber, especially by the RSFR. This is consistent with the results of the capacity of recycled waste tires to absorb energy during fracture (Centonze 2012, Aiello 2009, Eldin 1993).

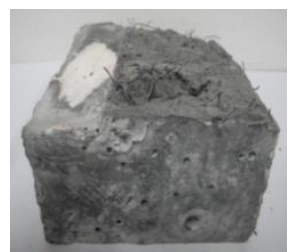

(a) HF1

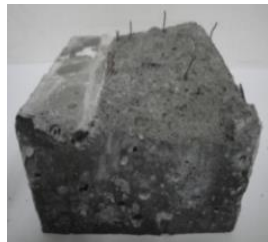

(b) HF2

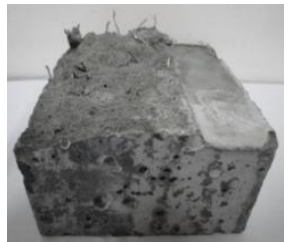

(c) HF3

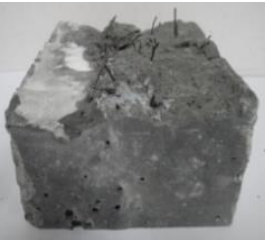

(e) RSF

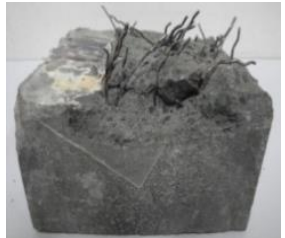

(f) RSFR

Figure 6. Morphology of steel fiber in the fracture surface of specimens after fracture energy testing 
The morphology of steel fiber at the fracture surface of a notched specimen, obtained from the fracture energy testing, are shown in figure 6. It illustrated that the exposed part of RSFR was the longest one among the various steel fiber. The exposed part of steel fiber was the pulled-out length of steel fiber during fracture energy testing. The larger the length of the pulled-out part of steel fiber, the longer the absorbed energy process, more energy consumed for fracture of UHPC during the testing, given the same dosage of steel fiber.

The load-deflection curves of all concretes are shown in figure 7. The peak load of UHPC with RSFR or RSF was not the highest among the steel fiber reinforced UHPC, but the area under load-deflection curve was much larger than that of UHPC with the three types of industrial steel fiber. Fracture energy of UHPC was enhanced by the recycled steel fiber remarkably, due to their much better post-peak loading toughness than that of the industrial steel fiber.

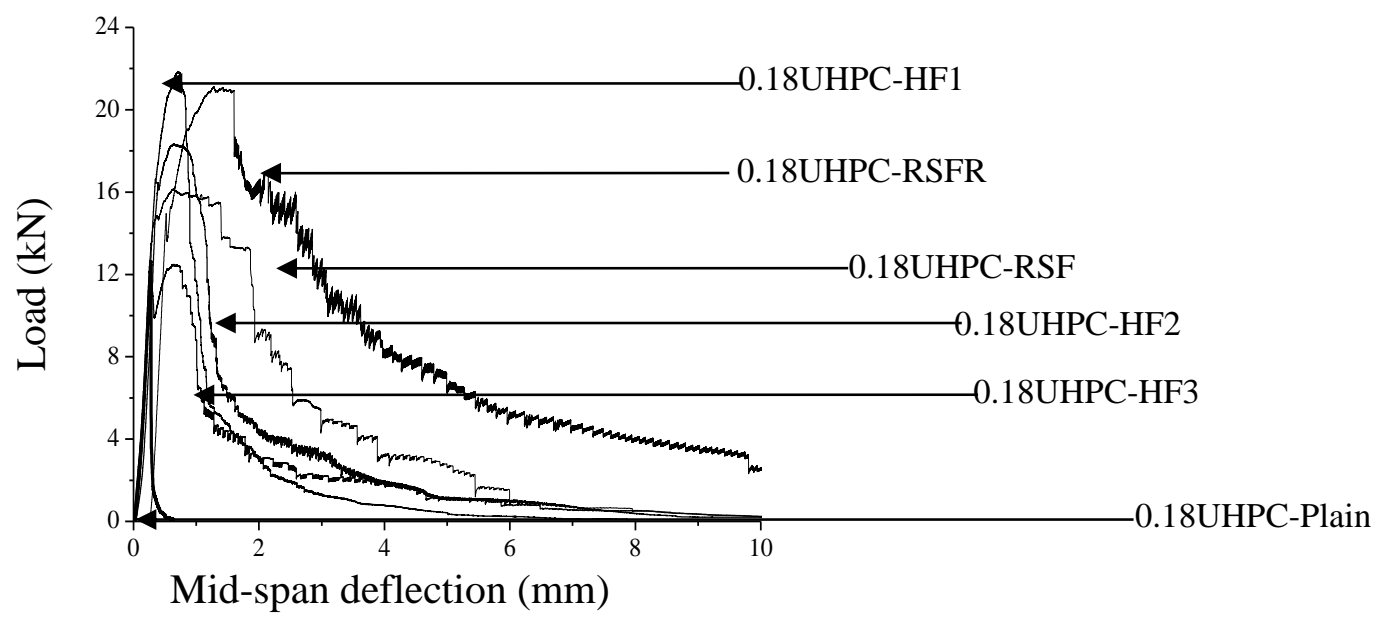

Figure 7. Load-deflection curves of UHPC with various steel fibers and the plain concrete during fracture energy testing on notched specimen

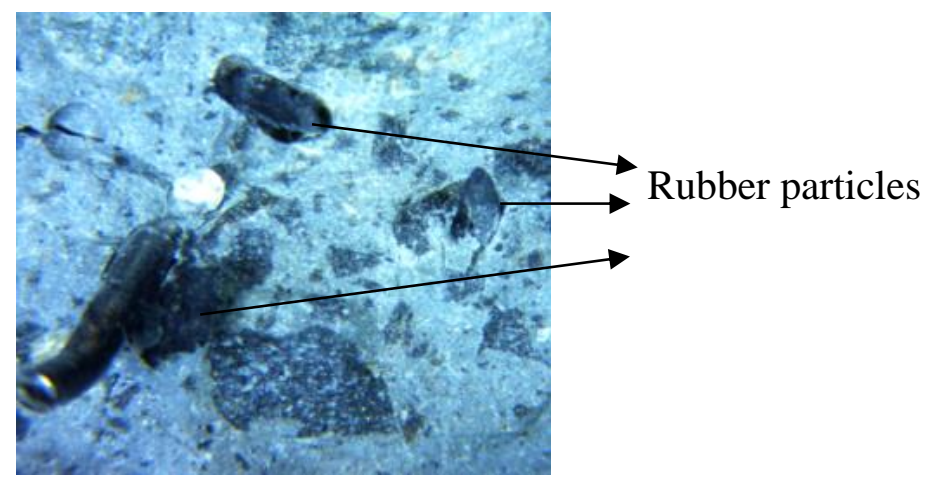

Figure 8. Rubber particles at a fracture surface of notched specimen after fracture energy test

RSFR presented better post-peak loading toughness than RSF. The rubber attached to the surface of RSFR can improve the bond strength between the RSFR and concrete matrix. As shown in figure 8, the rubber was still embedded in the matrix after steel fiber had been pulled out. 


\section{Explosive spalling}

The results of the explosive spalling tests of all concretes are listed in Table 7. It can be seen from Table 7 that the plain UHPC encountered severe explosive spalling, and all six specimens spalled. The addition of steel fiber can alleviate explosive spalling, especially types of the recycled steel fiber and the industrial steel fiber of HF1, where only three specimens spalled.

The spalling depth of the specimens was measured, as given in figure 9. The average spalling depth was the average value of the maximum spalling depth of the six cube specimens a group. If no spalling occurred, the spalling depth of specimen was $0 \mathrm{~mm}$, and if a specimen broke into many small fragments due to spalling, the spalling depth of specimen was $100 \mathrm{~mm}$, as given in figure 10 .

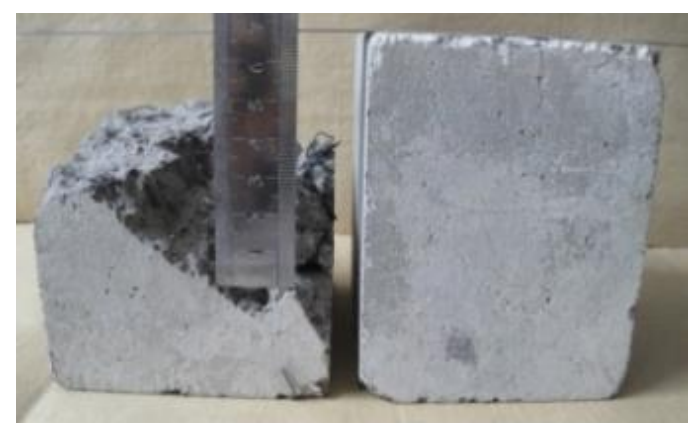

Figure 9. Determination of the spalling depth of specimen subjected to $800{ }^{\circ} \mathrm{C}$

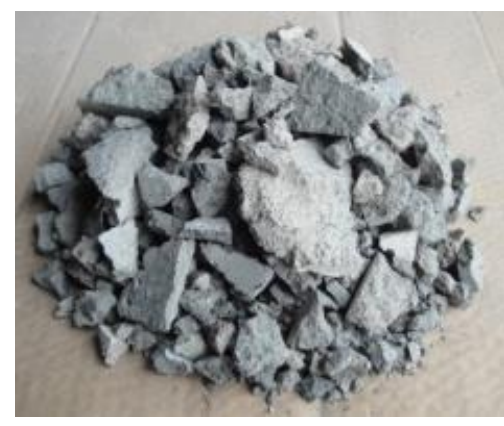

Figure 10. A severely spalled specimen

Table 7. Statistical results of explosive spalling tests on all concretes

\begin{tabular}{|c|c|c|}
\hline Type of concrete & Spalling frequency & Average spalling depth (mm) \\
\hline 0.18 UHPC-Plain & $6(6) * *$ & 92 \\
\hline 0.18 UHPC-HF1 & $3(6)$ & 82 \\
\hline 0.18 UHPC-HF2 & $5(6)$ & 76 \\
\hline 0.18 UHPC-HF3 & $5(6)$ & 27 \\
\hline 0.18 UHPC-RSF & $3(6)$ & 36 \\
\hline 0.18 UHPC-RSFR & $3(6)$ & \\
\hline
\end{tabular}

** The data inside the brackets is the amount of the total specimens for each condition. That outside the brackets is the number of specimens suffered explosive spalling. 


\section{Morphology of spalled specimens}

The morphology of all specimens after spalling test was shown in figure 11. The observation indicated that recycled steel fiber, as well as the industrial steel fiber of HF1, can improve the spalling-resistance of UHPC, and the RSF had a better effect than that of RSFR. Melted rubber on the surface of RSFR could become many channels, which released the vapor pressure resulted from high temperature, and explosive spalling was alleviated (Guo 2014).

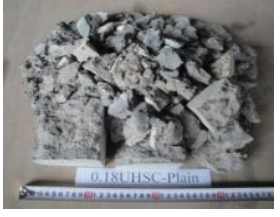

(a) 0.18UHPC-Plain

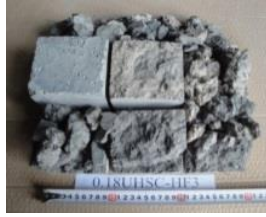

(d) $0.18 \mathrm{UHPC}-\mathrm{HF} 3$

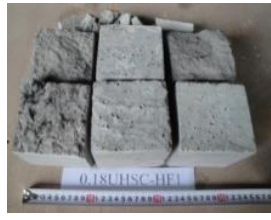

(b) 0.18UHPC-HF1

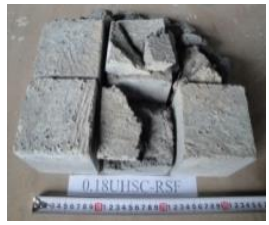

(e) 0.18UHPC-RSF

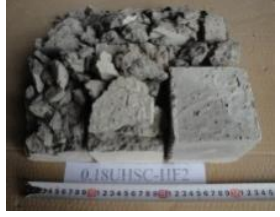

(c) $0.18 \mathrm{UHPC}-\mathrm{HF} 2$

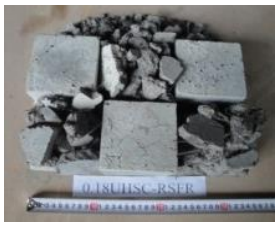

(f) 0.18UHPC-RSFR

Figure 11. Morphology of all types of UHPCs after being subjected to $800{ }^{\circ} \mathrm{C}$

HF1 performed quite well in alleviating spalling occurrence. This may be attributed to its larger aspect ratio. If the dosage and length of various steel fibers are the same, the number of steel fibers in a given concrete specimen will depend on the diameter of this type of steel fiber. It was calculated that the number of steel fibers of HF1 within a $100 \mathrm{~mm}$ cube specimen was about 441 and 150 for the two types of industrial steel fiber. It is estimated that the more intensive the distribution of steel fiber, the higher the crackingresistance of the steel fiber reinforced concrete.

\section{CONCLUSION}

The following conclusions are drawn from the present experimental research.

- Compressive strength of UHPC is increased by adding steel fiber, except for the RSFR. The increment of compressive strength of UHPC varies with the types of steel fiber.

- Steel fiber can improve splitting tensile strength of UHPC remarkably. The effect of RSFR is more pronounced than that of RSF, and splitting tensile strength of UHP with RSFR is the highest among the six types of concrete tested.

- Fracture energy of steel fiber reinforced concretes is higher than that of plain concrete, especially the concrete reinforced by the recycled steel fiber, which significantly improved fracture energy of UHPC. It is recommended that, recycled steel fiber can be used in ultra-high performance concrete.

- Steel fiber with the smallest diameter (HF1) shows the best effect on alleviating explosive spalling of UHPC. Meanwhile, recycled steel fiber presents a certain capacity to alleviate the explosive spalling of UHPC as well. 


\section{ACKNOWLEDGEMENTS}

The authors gratefully acknowledge the financial support of the National Science Foundation of China (Project Nos. 50978026, 51078030, and 51278048) and the financial support of the Fundamental Research Funds for the Central Universities of China (Project No: 2011YJS293).

\section{REFERENCES}

Azevedo, F., Pacheco-Torgal, Jesus, F., et al. (2012). "Properties and durability of HPC with tyre rubber wastes." Construction and Building Materials, 34(3), 186-191.

Aiello, M.A., Leuzzi, F., Centonze, G., et al. (2009). "Use of steel fibres recovered from waste tires as reinforcement in concrete: Pull-out behavior, compressive and flexural strength." Waste Management, 29(6), 1960-1970.

Bjegovic, D., Baricevic, A. \& Lakusic, S. (2012). "Innovative low cost fiber-reinforced concrete. Part I: Mechanical and durability properties."

Centonze, G., Leone, M. and Aiello, M.A. (2012). "Steel fiber from waste tires as reinforcement in concrete: A mechanical characterization." Construction and Building Materials, 36, 46-57.

Eldin, Nell N., Senouci, Ahmed B. (1993). "Rubber-tire particle as concrete aggregate." J. Mater. Civ. Eng, 5(4), 478-496.

Gesog`lu, M., Güneyisi, E., Khoshnaw, G., et al. (2014). "Investigating properties of pervious concretes containing waste tire rubbers." Construction and Building Materials, 63, 206-213.

Graeffang, A.G., Pilakoutas, K., Neocleous, K., et al. (2012). "Fatigue resistance and cracking mechanism of concrete pavements reinforced with recycled steel fibres recovered from post-consumer tires." Engineering Structures, 45, 385-395.

Guo, Y.C., Zhang, J.H., Chen, G.M., et al. (2014). "Compressive behavior of concrete structures incorporating recycled concrete aggregates, rubber crumb and reinforced with steel fibre, subjected to elevated temperatures." Journal of Cleaner Production, 72(6), 193-203.

Huang, X.Y., Ranade, R., Ni, W. \& Li, V.C. (2013). "On the use of recycled tire rubber to develop low emodulus ECC for durable concrete repairs." Construction and Building Materials, 46(8), 134-141.

Hosser, D., Kampmaier, B. \& Hollmann, D. (2012). "Behavior of ultra high performance concrete (UHPC) in case of fire." Proceedings of HiperMat/International Conference on UHPC and Nanotechnology Symposium on UHPC Construction Materials, 2012, 573-582.

Long, X.H. (2011). "Experimental research on mechanical properties of waste steel fiber rubber modified recycled aggregate concrete." Guangdong University of Technology.

Meddah, A., Beddar, M. \& Bali, A. (2014). "Use of shredded rubber tire aggregates for roller compacted concrete pavement." Journal of Cleaner Production, 72, 187-192.

Neocleous, K., Tlemat, H. \& Pilakoutas, K. (2006). "Design issues for concrete reinforced with steel fiber, Including fiber rrecovered from used tires." Journal of Materials in Civil Engineering, 18(5), 677-685.

Peng, G.F., Yang, W.W., Zhao, J., et al. (2006). "Explosive spalling and residual mechanical properties of fiber-toughened high-performance concrete subjected to high temperatures." Cement and Concrete Research, 36(4), 723-727. 
Peng, G.F., et al. (2008). "Function of steel fiber on restraining the spalling behavior of high strength concrete at high temperature." China Conference on Special Concrete Technologies and Engineering Applications, 2008, 566-571. (In Chinese)

Tortum, A., Celik, C. \& Cüneyt Aydin, A. (2005). "Determination of the optimum conditions for tire rubber in asphalt concrete." Building and Environment, 40(11), 1492-1504.

Tlemat, H., Pilakoutas, K. and Neocleous, K. (2006). "Stress-Strain Characteristic of SFRC Using Recycled Fiber." Materials and Structures, 39(3), 365-377.

Yung, W.H., Yung, L.C. \& Hua, L. H. (2013). "A study of the durability properties of waste tire rubber applied to self-compacting concrete." Construction and Building Materials, 41(2), 665-672. 